\title{
Instagram Virtual Network Addiction and Sleep Quality Among Students Pursuing a Speech and Hearing Course
}

\author{
Lancy D'Souza ${ }^{1, *}$ and Mohammad Bagher Negahban ${ }^{2,3}$ \\ ${ }^{1}$ Maharaja's College, University of Mysore, India \\ ${ }^{2}$ Shahid Bahonar University of Kerman, Kerman, Iran \\ ${ }^{3}$ Shiraz University of Medical Sciences, Shiraz, Iran \\ "Corresponding author: Associate Professor of Psychology, Maharaja's College, University of Mysore, Mysore-570 005, India. Email: lancyd@ymail.com
}

Received 2019 January 12; Revised 2019 March 04; Accepted 2019 March 04.

\begin{abstract}
Background: Currently the social networking application Instagram has taken higher priority of usage over many other such social networking applications.

Objectives: In the present study, an attempt was made to determine the relationship between Instagram addiction and sleep quality of students pursuing a speech and hearing course.

Methods: The present study adopted a correlational research design. The sample consisted of 110 students, comprised of 18 male and 92 female students aged between 17 and 25 years old from Mysuru city. Students pursuing a speech and hearing course completed the test for Instagram addiction (TIA) developed by D'Souza, Samyukta and Bivera, and Pittsburgh sleep quality index (PSQI) during September to November, 2018. Test for Instagram addiction measured addiction by considering six factors, including lack of control, disengagement, escapism, health and interpersonal troubles, excessive use, and obsession. The PSQI measured global sleep quality. Pearson's correlations were employed to find the relationship between dimensions of Instagram addiction and sleep quality. Stepwise multiple regression was employed to find the major predictors of sleep quality by factors of Instagram addiction. Results: The results revealed that among students pursuing speech and hearing selected for the study, only $0.9 \%$ were definitely addicts and $14.5 \%$ were 'addicts prone'. The majority of the selected sample (60.9\%) had healthy sleep quality. As addiction to Instagram increased, sleep quality of dental students decreased linearly and significantly $(r=0.536)$. 'Escapism' (29.8\%) and 'disengagement' (2.5\%) factors of test for Instagram addiction were found to be the major predictor (32.3\%) of sleep quality.

Conclusions: It was concluded that Instagram addiction affects sleep quality negatively.
\end{abstract}

Keywords: Instagram Addiction, Sleep Quality, Speech and Hearing Students

\section{Background}

Addiction is a condition, in which an individual takes part in the utilization of a substance or is in a conduct, for which the rewarding impacts give a convincing incentive to repeat the act over and over again regardless of harmful results. Addiction may include the utilization of substances, for example, liquor, inhalants, narcotics, cocaine, nicotine, and others, or behaviours, such as betting. There is logical proof that addictive substances and practices share a key neurobiological element; they seriously enact mind pathways of remuneration and fortification, a considerable lot of which include the dopamine synapses. One of the leading sources of addiction, which has effected youth in the recent years arises from the Internet. Internet addiction is defined as a pathological usage of the Internet and is characterized as an individual's failure to control his or her utilization of the Internet, which in the long run leads to problems in psychological, social, academic as well as in the work environment in an individual's life (1, 2 ). Internet addiction is a clear indication for unmanageable and harmful utilization of this innovation and it is a warning sign that an individual is experiencing issues in controlling his or her Internet usage (3). An estimate by 'Internet word stats' revealed that Internet penetration rate today is $55.1 \%$ around the world and growth is estimated at whopping $1066 \%$. According to Young (4), Internet addiction is an impulse control disorder, which does not include intoxication. The usage of intelligent screen media is widespread and for a few individuals, it leads to neurotic side effects that are phenomenological, and are indications of addictive issues. Different symptoms, include anger, strain, nervousness (5), and increased social maladjustment (6).

Internet addiction disorder (IAD) is quickly turning to 
a prevalent psychological wellbeing concern all over the world. Around $20 \%$ of adolescents have been reported to have Internet addiction (7), and around 45\% of school students have been reported by their wards on the issue of having at least one type of sleep problem (8). Addictionrelated sleep problems are prevalent and contribute to psychological and neurological diseases. Fineberg et al. (9), and Mahadevaswamy and D'Souza (10) in their study revealed that Internet addiction negatively influences psychological wellbeing of adolescents. Even personality of an individual may prone them to Internet or Facebook addiction $(11,12)$. In any case, Internet addiction did not influence subjective wellbeing of adolescents (13). Chen and Gau (14) highlighted in their study that students, who are addicted to the Internet have a greater chance of suffering from problems in their sleep. 'Neglect of work' and 'excessive use' of the Internet were found to be the best predictors of sleep quality. In another study, it was found that peer stress factor of academic stress was a major predictor of Internet addiction (15).

Instagram application has taken over many other such social networking applications. This is a photo sharing social networking app launched in the year 2010 and has more than one billion monthly active users worldwide, as of June 2018. Instagram has high levels of user engagement and one of the fastest growing social networking sites at present. This media provides a platform for sharing photographs, videos, and messages in a private and public way. One study found that people often post images with the hash-tag "\#”, which often communicate a person's emotional circumstances and also the shifts in commemorative and memorialization practices (16). This shows the new way of expression or feelings that people have obtained in the recent times. Another study, done on college students, revealed that the main reasons for Instagram use are "surveillance/knowledge about others," "documentation," "coolness," and "creativity." They also found that there is a positive relationship between using Instagram to be cool and for surveillance (17). Studies revealed that depression, anxiety, and Instagram addiction were related to each other $(18,19)$.

Today there are thousands of students, who are pursuing their education in speech and hearing. Like other students they may also be prone to Internet addiction on various applications, such as Instagram, Facebook, and so on, due to various issues.

\section{Objectives}

The present study attempted to find the relationship between Instagram addiction and sleep quality among speech and hearing students. There were no studies on speech and hearing of students regarding the relationship between Instagram addiction and sleep quality either at national or international level. Furthermore, the authors aimed at finding the possible predictors of sleep quality associated with Instagram addiction. It is hypothesized that Instagram addiction influences sleep quality and there will be definite predictors for sleep quality by factors of Internet addiction.

\section{Methods}

\subsection{Study Design}

The present study adopted a correlational research design. This is a type of non-experimental study, the researcher did not manipulate independent variables, and relationships were assessed.

\subsection{Sample}

Students pursuing their course in speech and hearing education at undergraduate level were selected for the purpose of the study. The data collection was done at a Speech and Hearing Institute, where there were approximately 150 users of Instagram. Using online sample size calculator (www.surveysystem.com/sscalc.htm), for a population of 150 students, using 95\% confidence level, and confidence interval of five, the required sample size was 108. A total of 110 students comprised of 18 male and 92 female students aged between 17 and 25 years were randomly selected using random generation of numbers by a computer. Their age varied with a mean age of $20.05 \pm 1.02$ years.

\subsubsection{Inclusion Criteria}

1. Speech and hearing of students using Instagram for more than six months

2. Students, who had access to the Internet for 24 hours a day

\subsubsection{Exclusion Criteria}

1. Students, who had opted to answer the TIA

2. Students suffering from some mild or moderate psychological disturbances

\subsection{Tools Employed}

\subsubsection{Test for Instagram Addiction (TIA)}

To measure the extent of Instagram addiction, TIA, developed by D'Souza et al. in the year 2018 was employed, consisting of 26 statements (20). The TIA measures Instagram addiction of an individual in six components, which include components such as lack of control, disengagement, escapism, health and interpersonal troubles, excessive use, and obsession. Furthermore, TIA has to be answered on a five-point Likert scale. The scores range from one to five, as follows: All the time (5), most of the time (4), 
sometimes (3), once in a while (2), and rarely/never (1). To find the reliability, the Cronbach's reliability test was performed and the alpha value obtained for the total inventory was 0.931 and for various components, it varied from 0.680 to 0.863 . Furthermore, when item to total scores correlations were performed, all the correlation coefficients obtained through Pearson's product moment correlation techniques were found to be highly significant, indicating that the TIA has high reliability and validity. Even the correlation coefficients obtained between components were found to be highly significant. High scores on the TIA indicate higher addiction to Instagram.

\subsubsection{The Pittsburgh Sleep Quality Index}

The Pittsburgh sleep quality index (PSQI-1989) was used to assess the extent of sleep quality among the selected sample (21). This scale contains 18 self-reporting items. The items measure seven components of sleep quality, score ranging from zero (no difficulty) to three (severe difficulty) for sleep duration, sleep disturbance, sleep latency, daytime disturbance, habitual sleep efficiency, sleep quality, and use of sleep medications. The total of these provide an index referred to as global sleep quality, which ranges from 0 to 21 . Reliability measures indicate that the PSQI generally has high internal consistency ( $\alpha=0.80$ to 0.85 ) and test-retest reliability ( $r=0.85$ to 0.87 ). It also has acceptable concurrent validity; scores on the PSQI are highly correlated with scores on other subjective measures of sleep quality $(r>0.69)$. The higher the score in PSQI indicates poor sleep quality. A score below five indicates poor healthy sleep quality and score five and above indicates poor sleep quality.

\subsection{Procedure}

After obtaining permission from the concerned authorities, both test for Instagram addiction and Pittsburgh sleep quality Index were administered to a total of 110 students pursuing speech and hearing courses in bachelor and master degree courses. Before administrating the questionnaire, they were assured of confidentiality. They were asked to answer all the questions.

Once the data were collected, they were scored and fed to the computer. The obtained data was analysed using Pearson's correlation and stepwise multiple regression analysis. Chi-squared tests were applied to find out the significance of differences between frequencies of extent of Instagram addiction and sleep quality.

\section{Results}

As stated in the background, the first objective of this research was to measure Instagram addiction and sleep quality to find out if there is a correlation between these two variables. Table 1 presents descriptive statistics for factors of TIA and PSQI. Table 2 shows the extent of Instagram addiction and sleep quality among the selected sample of students along with the results of chi-squared tests.

\subsection{Descriptive Statistics for Factors of Test for Instagram Addic- tion and PSQI}

Table 1 presents various levels of addiction to Instagram and sleep quality with score ranges, frequencies, percentages, and results of chi-squared tests.

As indicated in Table 2, in terms of Instagram addiction, the majority of the students pursuing the speech and hearing course had low to average usage. However, 14.5\% were prone to addiction and $0.9 \%$ were definitely addicted to Instagram. Chi-squared test revealed a significant difference in levels of Instagram addiction $\left(\chi^{2}=98.27 ; \mathrm{P}=\right.$ 0.0.001).

As far as sleep quality was analysed, Table 2 shows that the majority (60.9\%) of the sample had healthy sleep quality. The remaining 39.1\% had poor sleep quality. Chisquared test revealed a significant difference $\left(\chi^{2}=5.24 ; \mathrm{P}=\right.$ 0.022 ) between frequencies of healthy and poor sleep quality confirming that the majority had healthy sleep quality.

\subsection{Relationship Between Factors of TIA and Sleep Quality}

Sleep quality scores were significantly and positively related to all the factors of test for Instagram addiction (TIA). Sleep quality was found to be significantly and positively related to lack of control $(\mathrm{r}=0.462 ; \mathrm{P}=0.001)$, disengagement ( $\mathrm{r}=0.531 ; \mathrm{P}=0.001)$, escapism $(\mathrm{r}=0.552 ; \mathrm{P}$ $=0.001)$, health and interpersonal troubles $(\mathrm{r}=0.388 ; \mathrm{P}=$ $0.001)$, excessive use $(\mathrm{r}=0.302 ; \mathrm{P}=0.001)$, obsession $(\mathrm{r}=$ $0.236 ; \mathrm{P}=0.013)$ and total Instagram addiction scores $(\mathrm{r}=$ $0.536)$. In other words, as Instagram addiction both in individual dimensions and total scores increased, sleep quality decreased linearly and significantly.

\subsection{Regression Analysis}

The second objective of this study was to find possible predictors of sleep quality by various factors of Instagram addiction. Table 3 shows the results of stepwise multiple regression for sleep quality scores by various factors of Instagram addiction.

To find the major predictors of sleep quality by components of TIA, stepwise multiple regression was employed. When all the scores of six factors of Instagram addiction tests were regressed on the sleep quality scores, stepwise multiple regressions revealed that only two factors of TIA were found to be major predictors of sleep quality. The first factor entered in the equation was escapism with correlation coefficient of 0.552 , squared $R$ value of 0.304 


\begin{tabular}{|c|c|c|c|}
\hline Factors of TIA & Mean \pm SD & Minimum & Maximum \\
\hline 1. Lack of control & $12.00 \pm 5.10$ & 4 & 23 \\
\hline 2. Disengagement & $13.53 \pm 5.44$ & 6 & 29 \\
\hline 3. Escapism & $13.08 \pm 5.04$ & 5 & 25 \\
\hline 4. Health and interpersonal troubles & $5.98 \pm 2.77$ & 4 & 16 \\
\hline 5. Excessive Use & $3.24 \pm 1.80$ & 2 & 14 \\
\hline 6. Obsession & $9.35 \pm 3.91$ & 4 & 19 \\
\hline Total TIA scores & $57.10 \pm 19.70$ & 26 & 111 \\
\hline Sleep quality & $4.55 \pm 3.27$ & 0 & 14 \\
\hline
\end{tabular}

Abbreviation: PSQI, Pittsburgh sleep quality index; TIA, test for Instagram addiction.

Table 2. Extent of Instagram Addiction and Sleep Quality Among Dental College Students ${ }^{\mathrm{a}}$

\begin{tabular}{|cccc}
\hline Variable/Levels & Score Range & Frequency (\%) & $\chi^{2}$ \\
\hline Test for Instagram addiction & & & $98.27^{\mathrm{b}}$ \\
\hline 1. Nil/minimal & $<26$ & $2(1.8)$ & \\
\hline 2. Low & $27-52$ & $55(50.0)$ & \\
\hline 3. Average & $53-78$ & $36(32.8)$ & \\
\hline 4. Addict prone & $79-104$ & $16(14.5)$ & \\
\hline 5. Definitely addict & $105-130$ & $1(0.9)$ & \\
\hline Sleep quality & & & \\
\hline 1. Healthy & $<5$ & $67(60.9)$ & \\
\hline 2. Poor & $>5$ & $43(39.1)$ & \\
\hline
\end{tabular}

${ }^{\mathrm{a}} \mathrm{df}(\mathrm{TIA})=4 ; \mathrm{df}(\mathrm{SQ})=1$.

${ }^{\mathrm{b}} \mathrm{P}=0.001$.

${ }^{\mathrm{c}} \mathrm{P}=0.05$

and adjusted $\mathrm{R}^{2}$ value of 0.298 . The second factor of TIA to enter in the equation was disengagement along with escapism with combined correlation coefficient of 0.579 , squared $\mathrm{R}$ value of 0.335 , and adjusted $\mathrm{R}^{2}$ value of 0.323 . In other words, both escapism and disengagement factors of TIA contributed to $32.3 \%$ of the sleep quality among the present sample of students pursuing speech and hearing course. The beta values for the first predicted models escapism at steps I and II were 0.552 and 0.351 , respectively. The beta coefficient for the second predicted modeldisengagement was found to be 0.267 at step II.

\section{Discussion}

From the results, it is clear that among students pursuing speech and hearing, who were selected for the study, only $0.9 \%$ were definitely addicts and $14.5 \%$ were 'prone to addiction'. The majority of the selected sample (60.9\%) had healthy sleep quality. As addiction to Instagram increased, sleep quality of dental students decreased linearly and significantly. 'Escapism' and 'disengagement' factors of test for Instagram addiction were major predictors of sleep quality.

Recent studies clearly revealed that Instagram is the worst social media network for mental health and wellbeing, based on a research on almost 1500 individuals aged between 14 and 24 years old. Furthermore, it was found that Instagram addiction is associated with high levels of depression, anxiety, bullying, and fear of missing out phenomenon (FOMO). There are no studies directly related to Instagram addiction and sleep quality among speech and hearing students. However, in a recent study D'Souza et al. (22) found that among medical students, 5.7\% of the students were addicted to Instagram and $13.0 \%$ were prone to addiction. Comparatively, less addiction to Instagram was found by dental students than medical students. When compared to students pursuing non-professional courses, students pursuing dental and medical courses had lower addiction to Instagram (23-25).

Studies done by Ko et al. (7) found that adolescents' addiction to the Internet has resulted in many negative consequences, including academic failure, poor family relationships, impaired social functioning, emotional problems, and psychiatric problems. In a study carried out among medical university students in Malaysia, it was found that over $50 \%$ of the students either frequently or occasionally declared that their academic and job performance was affected because of Internet use. The authors believe that individuals, who score $<60 \%$ are probably spending the majority of their time on the Internet for socializing and chatting. They are not using it for academic purposes, therefore, their academic performance is affected. Hence, efforts need to be made to counsel students regarding the proper use of Internet for academic purposes (25). 


\begin{tabular}{|c|c|c|c|c|c|}
\hline Model & \multicolumn{2}{|c|}{ Unstandardized Coefficients } & \multirow[t]{2}{*}{ Standardized Coefficients, $\beta$} & \multirow[t]{2}{*}{$t$} & \multirow[t]{2}{*}{ P Value } \\
\hline & B & Standard Error & & & \\
\hline \multicolumn{6}{|l|}{$\mathbf{1}$} \\
\hline Constant & -0.141 & 0.730 & & -0.194 & 0.847 \\
\hline Escapism & 0.358 & 0.052 & 0.552 & 6.871 & 0.000 \\
\hline \multicolumn{6}{|l|}{2} \\
\hline Constant & -0.605 & 0.747 & & -0.809 & 0.420 \\
\hline Escapism & 0.228 & 0.078 & 0.351 & 2.926 & 0.004 \\
\hline Disengagement & 0.160 & 0.072 & 0.267 & 2.227 & 0.028 \\
\hline
\end{tabular}

${ }^{\mathrm{a}}$ Method: Stepwise: Alpha to enter into the equation 0.05 .

According to Fineberg et al. (9) "Addiction-related sleep problems and addiction are prevalent, and contribute to a notable fraction of the disease burden in mental and neurological disorders in established market economies". As far as sleep quality is concerned, 53.7\% of the selected sample had healthy sleep quality, however, $43.3 \%$ of the sample had poor sleep quality. D'Souza and Samyukta (26) in their study on college students found that $9.7 \%$ of the studied sample were Facebook addicts, and approximately $43 \%$ of the students selected in the present study had moderate to high Facebook addiction. Sleep problems and Internet addiction are common among children and adolescents, and are a major concern of parents. Ko et al. (7) reported that approximately $20 \%$ of youth are Internet addicts, and parental observation on elementary and junior high students revealed that about $45 \%$ of them had some kind of sleep problem (8). Hence, verifying the long-term associations between sleep problems and Internet addiction may lead to prevention and treatment strategies for improving sleep quality and reduction of Internet addiction. In Nepal, it was found that Internet addiction mediated $16.5 \%$ of the indirect effect of sleep quality on depressive symptoms among undergraduate students (27).

Results clearly revealed that Instagram addiction was directly related to sleep quality in individual factors as well as total Instagram addiction scores. Since there were not many studies directly related to Instagram addiction and sleep quality, the authors could find only studies related to social media addiction, Facebook addiction etc., on sleep quality. A recent study revealed that as Internet addiction increased, sleep quality of female students decreased linearly and significantly (28). Chen and Gau (14), after a longitudinal study on sleep problems and Internet addiction, concluded that insomnias sequentially predicted Internet addiction, and Internet addiction sequentially predicted disturbed circadian rhythm. Young people with insomnia may spend the time they struggle to sleep with Inter- net use, yet this in turn can lead to circadian rhythm disturbances, possibly through the effects of light at adverse times.

To conclude, the influence of Internet and social media plays a major role in the lives of speech and hearing students. Internet addiction is gradually increasing and the probable reason might be due to advanced technologies, such as smart phones, digital watches etc. However, lack of control and excessive use may affect their sleep quality. Once sleep quality is affected, it has a direct link with mental health issues. Instagram and similar social media applications must be used with caution, so that Instagram should serve as a potential tool in improving the mental health of individuals and not the detrimental one.

\section{Footnotes}

Authors' Contribution: Lancy D'Souza developed the research methodology, performed the statistical analysis and authored the conclusion. Mohammad Bagher Negahban collected the required data, developed the statement of problem and literature review. Both authors contributed to the final version of the manuscript.

Conflict of Interests: The authors declare that there is no conflict of interest in this study.

Ethical Approval: The study protocol was consistent with the ethical guidelines of the 1975 Declaration of Helsinki as reflected in a prior approval by the Institution's Human Research Committee.

Funding/Support: There was no support or funding for this research article.

Patient Consent: Informed consent was obtained from each participant included in the study. 


\section{References}

1. Davis RA. A cognitive-behavioral model of pathological Internet use. Comput Human Behav. 2001;17(2):187-95. doi: 10.1016/s07475632(00)00041-8.

2. Young KS, Rodgers R. Internet addiction: Personality traits associated with its development. 69th Annual Meeting of the Eastern Psychological Association. 1998.

3. Beard KW. Internet addiction: Current status and implications for employees. J Employ Couns. 2002;39(1):2-11. doi: 10.1002/j.21611920.2002.tbo0503.x

4. Young K. Internet addiction scale. 1998. Available from: www.globaladdiction.org.

5. Goldberg I. Internet addictive disorder (IAD) diagnostic criteria. 1995. Available from: www.psycom.net/iadcriteria.html.

6. Chandrashekhar D, D'Souza L. Influence of shyness on social and emotional adjustment among adolescents. United J Awadh Sch. 2013;7:4-10.

7. Ko CH, Yen JY, Chen CC, Chen SH, Yen CF. Proposed diagnostic criteria of Internet addiction for adolescents.J Nerv Ment Dis. 2005;193(11):72833. [PubMed: 16260926]

8. Shur-Fen Gau S. Prevalence of sleep problems and their association with inattention/hyperactivity among children aged 6-15 in Taiwan. J Sleep Res. 2006;15(4):403-14. doi: 10.1111/j.1365-2869.2006.00552.x. [PubMed: 17118097].

9. Fineberg NA, Haddad PM, Carpenter L, Gannon B, Sharpe R, Young $\mathrm{AH}$, et al. The size, burden and cost of disorders of the brain in the UK.J Psychopharmacol.2013;27(9):761-70. doi:10.1177/0269881113495118. [PubMed: 23884863]. [PubMed Central: PMC3778981].

10. Mahadevaswamy P, D'Souza L. Effect of internet addiction on psychological wellbeing among adolescents. Int J Psychol Psychiatry. 2017;5(2):76-86. doi: 10.5958/2320-6233.2017.00012.8.

11. D'Souza L . Personality correlates of Facebook addiction among college student. 5th Academic Conference on Social Sciences. Singapore. 78th July, 2018.

12. D'Souza L, Ravi M, Lakshmeesh DM, Singh M. Shyness correlates of Facebook addiction among college students. Int J India Psychol. 2018;6(3):96-103.

13. Mahadevaswamy P, D'Souza L. Effect of internet addiction on subjective well-being among adolescents. Asian J Dev Matters. 2017;11(1):73-81.

14. Chen YL, Gau SS. Sleep problems and internet addiction among children and adolescents: A longitudinal study.JSleep Res. 2016;25(4):45865. doi: 10.1111/jsr.12388. [PubMed: 26854132]
15. D'Souza L, Manish S. Relationship between academic stress and internet addiction among college students. Int J India Psychol. 2018;6(2):100-8.

16. Gibbs M, Meese J, Arnold M, Nansen B, Carter M. \#Funeral and Instagram: Death, social media, and platform vernacular. Inf Commun Soc. 2014;18(3):255-68. doi:10.1080/1369118x.2014.987152.

17. Sheldon P, Bryant K. Instagram: Motives for its use and relationship to narcissism and contextual age. Comput Human Behav. 2016;58:8997. doi: 10.1016/j.chb.2015.12.059.

18. D'Souza L, Hemamalini MJ. Instagram addiction and depression among college students. Int J India Psychol. 2018;6(4):96-102.

19. D'Souza L, Hemamalini MJ. Does anxiety influences instagram addiction among college students? Int J India Psychol. 2018;6(4):167-73.

20. D'Souza L, Samyukta A, Bivera TJ. Development and validation of test for Internet addiction (TIA). Int J India Psychol. 2018;6(3):4-14.

21. Buysse DJ, Reynolds CF 3rd, Monk TH, Berman SR, Kupfer DJ. The pittsburgh sleep quality index: A new instrument for psychiatric practice and research. Psychiatry Res. 1989;28(2):193-213. [PubMed: 2748771].

22. D'Souza L, Rekha MS, Sowmya HR. Relationship between Instagram addiction and sleep quality among medical students. Commun PakJ Psychol Res. 2018.

23. D'Souza L. Instagram addiction among students pursuing paramedical and non-professional students: A comparative study. Int JIndia Psy chol. 2018;6(2):69-75.

24. D'Souza L, Sowmya HR. Instagram addiction among students pursuing medical and non-professional courses: A comparative study. Int J India Psychol. 2018;6(4):4-10.

25. Haque M, Rahman NA, Majumder MA, Haque SZ, Kamal ZM, Islam Z, et al. Internet use and addiction among medical students of Universiti Sultan Zainal Abidin, Malaysia. Psychol Res Behav Manag. 2016;9:297307. doi: 10.2147/PRBM.S119275. [PubMed: 27881928]. [PubMed Central: PMC5115623].

26. D'Souza L, Samyukta A. Extent of Facebook addiction among college students: Influence of select demographic factors. Int J India Psychol. 2018;6(3):4-10.

27. Bhandari PM, Neupane D, Rijal S, Thapa K, Mishra SR, Poudyal AK. Sleep quality, internet addiction and depressive symptoms among undergraduate students in Nepal. BMC Psychiatry. 2017;17(1):106 doi: 10.1186/s12888-017-1275-5. [PubMed: 28327098]. [PubMed Central: PMC5361804].

28. D'Souza L, Samyukta A, Tejaswini SM. Relationship between Internet addiction and sleep quality among female students. Int J India Psychol. 2018;6(1):83-8. 